\title{
Reducing Surfactants-Silica Interactions for High-Coverage Silane-Modification of MCM-41 and MCM-48 Silicas
}

\author{
Hong-Ping Lin, ${ }^{\dagger, *}$ Pei-Chun Shih, ${ }^{\dagger \dagger, \dagger \dagger}$ Yi-Hsin Liu, ${ }^{\dagger \dagger}$ and Chung-Yuan Mou ${ }^{\dagger \dagger}$ \\ ${ }^{\dagger}$ Institute of Chemistry, Academia Sinica, Nankang, Taipei, Taiwan 115 \\ ${ }^{\dagger}$ Department of Chemistry and Center of Condensed Matter Science, National Taiwan University, Taipei, Taiwan 106 \\ ${ }^{+\dagger}$ Deh Yu College of Nursing and Management, Keelung, Taiwan 203
}

(Received January 28, 2002; CL-020100)

Reducing surfactants-silica interactions in the acid solution provides a novel and efficient strategy for obtaining highcoverage silanes grafted MCM-41 or MCM-48 mesoporous materials and a simultaneous recovery of the surfactants under a mild modification condition.

To extend the applications of the mesoporous silicas of highperformance advantages (such as high surface area, tunable pore size, and uniformed pore) in catalyst, absorbent and chemical sensors, surface modification is essentially required.$^{1-4}$ However, it is really important to maintain a large number of surface silanol groups $(\mathrm{Si}-\mathrm{OH})$ on the mesoporous silica wall after the removal of the surfactant when a high surface coverage of functional groups is preferred. In general, a complete removal of the organic surfactant for MCM-41 and MCM-48 mesoporous materials prepared from alkaline media was carried out by hightemperature calcination due to the strong electrostatic interactions between negative charged silica $\left(\mathrm{I}^{-}\right)$and cationic quaternary ammonium surfactant $\left(\mathrm{C}_{\mathrm{n}} \mathrm{TMA}^{+} ; \mathrm{S}^{+}\right){ }^{5,6}$ But, calcination always provokes the surface silanol groups to condense further that dramatically reduces the $\mathrm{Si}-\mathrm{OH}$ density as reactive sites for surface modification. Although many methods attempted to recover the high silanol density by adding a trace amount of water, ${ }^{1}$ the procedures and composites are complicated and difficult to be optimized. Calcination wholly burns up and wastes the expensive quaternary ammonium surfactants. Thus, an efficient and economic method to prepare MCM-41 and MCM48 mesoporous silicas with high surface silane-modification and recovery surfactant remains desired.

It should be noteworthy that the MCM-41 and MCM-48 silica-surfactant mesoporous silicas in real are not the covalentbonding composites. ${ }^{7}$ Thus, the interactions between the silica and surfactant could be tunable by adjusting $\mathrm{pH}$ value. ${ }^{8}$

In this study, first, we shifted the strong electrostatic interactions $\left(\mathrm{S}^{+} \mathrm{I}^{-}\right)$between the surfactants and silica wall of alkaline-made MCM-41 and MCM-48 samples to a weak hydrogen-bonding form $\left(\mathrm{S}^{+} \mathrm{X}^{-\cdots} \mathrm{I}^{0}\right)$ via a simple acidic $(\mathrm{pH}<1)$ treatment procedure. ${ }^{9}$ The dry base-made MCM-41 and MCM-48 samples were combined with nitric acid water solution $(\mathrm{pH}<1)$, where the weight ratio of sample to acidic solution is $1: 50$, and then stirred at room temperature for $1-2$ days. After filtration, washing and drying at $100^{\circ} \mathrm{C}$, the dried acid-treated MCM-41 and MCM-48 samples were obtained.

To rationalize the interaction transformation of the mesoporous surfactants-silicas composites, we rationally compared the IR spectra of the MCM-41 and MCM-48 mesoporous silicas before and after nitric acid solution treatment (Figure 1A, spectra I, II). One can obviously find the existence of an extra strong absorption band of nearly $1350 \mathrm{~cm}^{-1}$ denoted by an arrow in the acid-treated MCM-48 sample, which was attributed to the vibration mode of $\mathrm{NO}_{3}{ }^{-}$ions. This qualitatively reveals that interactions of the silica-surfactant were changed from an electrostatic mode of $\mathrm{S}^{+} \mathrm{I}^{-}$to hydrogen bonding $\mathrm{S}^{+} \mathrm{NO}_{3}{ }^{-} \mathrm{I}^{0}$ form. With a quantitative elemental analysis, the N/C ratio in the acid-treated mesoporous sample was found to be nearly twice as many as those before acid treatment interaction, indicating an almost total transformation from $\mathrm{S}^{+} \mathrm{I}^{-}$to $\mathrm{S}^{+} \mathrm{NO}_{3}{ }^{-} \mathrm{I}^{0}$ form. In addition, the XRD patterns of the acid-treated mesoporous are almost the same as the original mesostructures. (Figure 1B, C) Thus, it is rational to schematically propose a complete interaction transformation process as below:
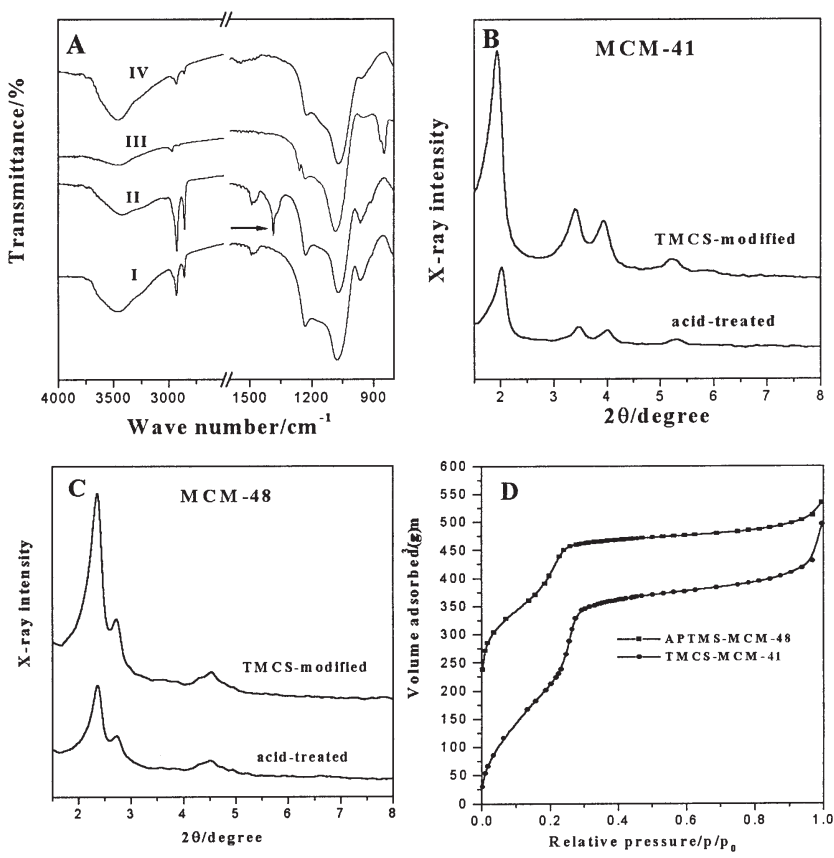

Figure 1. (A) The IR spectra of the based-made mesoporous silica (I), acid-treated mesoporous silica (II), TMCS-modified mesoporous silica (III), APTMS-modified mesoporous silica (IV). (B) XRD patterns of the MCM-41 before and after TMCS-modification. (C) MCM-48 mesoporous silicas before and after TMCS-modification. (D) The $\mathrm{N}_{2}$ adsorption-desorption isotherms of the silane-modified MCM-41 and MCM-48 mesoporous silicas. 


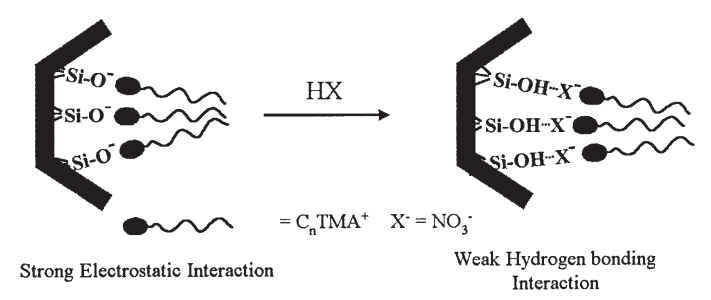

It is well known that the adsorbed water usually induces a non-uniform grafting upon surface modification. Typically, a moisture-free condition and dried solvent are necessary for calcinated and surfactant-free mesoporous samples. However, the existence of the surfactants inside the nanochannels could prevent a capillary-adsorption of water from atmosphere by empty nanochannels. Besides, due to the weak hydrogen-bonding interactions of $\left(\mathrm{S}^{+} \mathrm{X}^{-\cdots} \mathrm{I}^{0}\right)$, it was supposed that surface modification of the acid-treated MCM-41 and MCM-48 mesoporous silicas could be achieved under a mild condition as well as the acid-synthesized mesoporous silicas. ${ }^{10}$ Accordingly, these two unique advantages would make a homogeneous silanemodification easily achieved in a polar ethanol solution. For surface silane-modification, a proper amount of dried and acidtreated mesoporous sample was embedded into the silane ethanol solution and refluxed for $3-6 \mathrm{~h}$ at about $70^{\circ} \mathrm{C}$. The products were recovered by filtration, washed with a large amount of ethanol and dryed. The silanes sources are TMCS $\left(\mathrm{Me}_{3} \mathrm{SiCl}\right)$, MPTMS $\left(\mathrm{HS}\left(\mathrm{CH}_{2}\right)_{3}-\mathrm{Si}(\mathrm{OMe})_{3}\right)$, or APTMS $\left(\mathrm{H}_{2} \mathrm{~N}\left(\mathrm{CH}_{2}\right)_{3}-\mathrm{Si}(\mathrm{OMe})_{3}\right)$.

After TMCS and MPTMS grafting, the intensity of $\mathrm{C}-\mathrm{H}$ stretching band $\left(3000-2800 \mathrm{~cm}^{-1}\right)$ of the surfactants dramatically decreased, the adsorption band of $\mathrm{NO}_{3}{ }^{-}$disappeared in the IR spectra (Figure 1A, spectra III, IV) and no N element content was detected from elemental analysis, indicating a nearly complete replacement of quaternary ammonium surfactant by TMCS and MPTMS silanes. Therefore, the quaternary ammonium surfactants were easily recovered in a high recovery yield of $>95 \%$ from the ethanol solution and reused for mesoporous silica preparations. Moreover, the TMCS grafted mesoporous MCM-41 and MCM-48 have an obvious increase of the XRD peak intensity and number of peaks (Figure 1B, and $\mathrm{C}$ ), responding to the surfactant removal and an increase of the electron density difference between silicas wall and surfactant-free pore. The $\mathrm{N}_{2}$ adsorption-desorption isotherms of the silane-modified were examined as well. Figure 1D demonstrates that both the APTMS and TMCS silane-modified MCM-48 possess the sharp capillary condensations and high pore volume.

The physical properties of the silane-modified MCM-41 and MCM-48 including the pore size BET surface area and pore volume are listed in Table 1. From the data, we can find that the silane-grafted samples exhibit the advantages of large surface area, pore size and porosity as the typical mesoporous silicas. The silane coverage estimated from a calculation of the carbon content of elemental analysis data is in the range of $2.0-3.5 \mathrm{mmol} / \mathrm{g}$. The high silane-coverage was due to the preservation of surface $\mathrm{Si}-\mathrm{OH}$ groups of the nanochannels.

Basically, this two-step process provided a low-energy mechanism (i.e. hydrogen bonding interaction $\rightarrow$ covalent chemical bond) of silane-modification for the base-made mesoporous materials. In contrast, a high-temperature condition,
Table 1. The physical properties of BET surface area, pore size, pore volume and the carbon contents of the silane-grated MCM-41 and MCM-48 mesoporous materials

\begin{tabular}{|c|c|c|c|c|}
\hline Samples & $\begin{array}{l}\text { S. A. } \\
/ \mathrm{cm}^{2} / \mathrm{g}\end{array}$ & $\begin{array}{c}\text { Pore size } \\
/ \AA\end{array}$ & $\begin{array}{l}\text { Pore volume } \\
\qquad / \mathrm{cm}^{3} / \mathrm{g}\end{array}$ & $\begin{array}{c}\text { Carbon } \\
\text { content } \\
1 \%\end{array}$ \\
\hline MCM- $41^{\mathrm{a}}$ & 1058 & 27.0 & 0.61 & 0 \\
\hline TMCS-41 & 786 & 24.8 & 0.51 & 7.80 \\
\hline APTMS-41 & 720 & 21.6 & 0.39 & 9.89 \\
\hline MPTMS-41 & 680 & 20.8 & 0.36 & 10.66 \\
\hline $\mathrm{MCM}-48^{\mathrm{a}}$ & 1054 & 23.0 & 0.63 & 0 \\
\hline TMCS-48 & 823 & 19.0 & 0.58 & 11.86 \\
\hline APTMS-48 & 760 & 17.3 & 0.39 & 11.20 \\
\hline MPTMS-48 & 720 & 16.2 & 0.37 & 14.71 \\
\hline
\end{tabular}

${ }^{a}$ The calcinated mesoporous samples as the blank. ${ }^{b} \mathrm{~N}_{2}$ adsorption volume at $\mathrm{p} / \mathrm{p}_{0}=0.9{ }^{\mathrm{c}}$ Data from elemental analysis.

long reaction time $(>10 \mathrm{~h}$ ) and complicated composites (such as: concentrated silanes solution and the charge-balanced silanes) have to be performed to overcome a high-activation-energy replacement for silane-modification of the base-made MCM-41 mesoporous silicas (i.e. electrostatic interaction $\rightarrow$ covalent chemical bond). ${ }^{11}$

In conclusion, we proposed a convenient and economic twostep process for preparing high-coverage silane-grafted MCM-41 and MCM-48 silicas. Due to the existence of the surfactant in the nanochannels, this process becomes versatile in the grafting of water-sensitive silane compounds or metal alkyloxides. Therefore, the reduction of surfactants-silica interaction opens another newly judicious route for the silane-modification of the basemade mesoporous silicas with various hierarchical morphologies and mesostructures. ${ }^{12}$ Besides, the interactions between silica and surfactants have been reversibly adjusted by changing the charge properties of the silicas in a media of different $\mathrm{pH}$ value, one can logically design a well-organized reaction process for effortlessly getting the preferred mesoporous products for versatile applications.

\section{References}

1 L. Q. Wang, G. J. Exarhos, and J. Liu, Adv. Mater., 11, 1331 (1999).

2 A. Stein, B. J. Melde, and R. C. Schroden, Adv. Mater., 12, 1403 (2000).

3 K. Moller, and T. Bein, Chem. Mater., 10, 2950 (1998).

4 K. A. Koyano, T. Tatsumi, Y. Tanaka, and S. Nakata, J. Phys.Chem. $B, \mathbf{1 0 1}, 9436$ (1997).

5 C. T. Kresge, M. E. Leonowicz, W. J. Roth, J. C. Vartuli, and J. S. Beck, Nature, 359, 710 (1992).

6 R. Ryoo, S. H. Joo, and J. M. Kim, J. Phys. Chem. B, 103, 7435 (1999).

7 Q. Huo, D. I. Mergolese, U. Ciesla, D. G. Demuth, P. Feng, T. E. Gier, P. Sieger, A. Firouzi, B. F. Chmelka, F. Schuth, and G. D. Stucky, Chem. Mater., 6, 1176 (1994).

8 H. P. Lin, C. Y. Mou, and S. B. Liu, Adv. Mater., 12, 103 (2000).

9 R. K. Iler, "The chemistry of silica," Wiley, New York (1979).

10 H. P. Lin, L. Y. Yang, C. Y. Mou, S. B. Liu, and H. K. Lee, New J. Chem., 24, 253 (2000).

11 a) V. Antochshuk and M. Jaroniec, Chem. Mater., 12, 2496 (2000). (b) S. Dai, Y. Shin, Y. Ju, M. C. Burleigh, J.-S. Lin, E. Barnes, and Z. Xue, Adv. Mater., 11, 1226 (1999).

12 H. P. Lin and C. Y. Mou, Pure Appl. Chem., 72, 137 (2000). 